\title{
The vulnerability of orphans in Thyolo District, southern Malawi
}

\author{
Å. FUNKQUIST ${ }^{1}$, BODIL ERIKSSON ${ }^{2}$ and A.S. MUULA ${ }^{3^{*}}$ \\ ${ }^{2}$ Lund University, Sweden \\ ${ }^{3}$ Umeå University, Sweden \\ ${ }^{3}$ Department of Community Health, University of Malawi College of Medicine, Private Bag 360, Chichiri, \\ Blantyre 3, Malawi
}

\begin{abstract}
It is estimated that Malawi has about 900,000 orphans, the majority of whom are orphaned as a result of AIDS. Orphans in rural areas are mostly neglected by economic and social empowerment initiatives. This study was conducted to explore the living situation of orphans in rural Thyolo District, southern Malawi. Qualitative methodology was used in data collection and analysis to explore orphan children's living situation and specifically with regard to access to health care, education, food and basic needs. In addition, issues of love and companionship, discrimination and the future. Twenty-three orphan children and four adults were interviewed. The children reported experience with lack of food, school drop out and truancy, lack of social support to obtain present needs and prepare for the future. Public health programs aimed to prevent and mitigate the effects of AIDS in Malawi should be tailored to provide support to orphan children.
\end{abstract}

Keywords: orphans, HIV / AIDS, discrimination, living situation, Malawi

\section{Introduction}

The HIV / AIDS epidemic is a serious health and development problem in many countries around the world, especially in Africa. Since the HIV epidemic is primarily affecting young adults, particularly women, it is dramatically changing the demographic and household structures in heavily affected countries (UNAIDS, 2006). Delva et al. (2005) have estimated that by 2010, 1 in 5 children will be orphaned in Botswana, Lesotho, Swaziland and Zimbabwe. This has already been demonstrated in Manicaland, Zimbabwe where one in 5 households in 1998 had an orphan (Drew et al., 1998).

Unlike in some parts of the world such as Egypt where children mostly become orphans out of abandonment (Gibbons, 2005), in southern Africa, being an orphan is mostly due to death of parents. One of the serious consequences of the HIV / AIDS epidemic is the orphan crises Malawi is facing today. An orphan is defined as a child who has lost one or both parents because of death and is aged 18 years or below (UNICEF \& UNAIDS, 1999). With this definition, there are approximately 900,000 orphans in Malawi, which is almost $10 \%$ of the country's population (National AIDS Commission, 2005). In 2005, it was estimated that $40 \%$ of the orphans had lost their parents due to AIDS, and this figure will probably continue to rise unless the spread of HIV decreases. There have been reports of decreasing incidence (new HIV cases), in some cases stabilisation of new cases in some settings in Eastern and Southern Africa (Brody, 2004; Michelo et al., 2006; Murphy et al., 2006). The reasons for the declines in incidence or prevalence are issues for controversial debate.

Muula et al. (2003) have reported that many orphans are being cared for by their grandparents or they take care of themselves. Some families are headed by children 10 years old or younger and this has led to a declining standard of care for these children. Orphan care in Malawi lacks the resources to provide adequate services such as education and healthcare to most orphans. These orphans will in the future translate into diminished human capital and less disposable income once they start working. As a result Malawi's economy will not expand as fast as it would have done without the orphan crises (World University Service of Canada, 2004).

The main objective of this study was to obtain an understanding of the life situation for orphans aged 10-15 years in rural southern Malawi. The research work also attempted to highlight the special needs of children living without their parents and also to determine if the children were experiencing discrimination in any way and how they perceived their own situation. In order to understand these issues, we identified the following areas as pertinent to the life of the orphan child in rural Malawi: education, food, healthcare, clothing and other daily necessities, friends, love and care, labour and perceptions about the future. 


\section{Materials and Methods}

\section{Study area}

The study was conducted in Thyolo, a rural district in southern Malawi. HIV infection rates, community practice in the treatment of sexually transmitted infections, the availability and role of traditional healers and the scaling up of antiretroviral therapy for the treatment of AIDS have been described elsewhere (Manzi et al., 2005; Zachariah et al., 2001, 2006). The study was conducted in Helemani village, situated approximately $100 \mathrm{~km}$ south of the City of Blantyre. Helemani village was chosen because of its geographical location. The village is next to the Malamulo Hospital. The study was conducted such that any findings may be of use to the homebased care services at the hospital. The close proximity between the village and the hospital could potentially be valuable for intervention program provision.

\section{Data collection}

We used a qualitative method because of the explorative nature of the issues and need to obtain in-depth understanding of the situation (Mikkelsen, 1995). Individual interviews with 23 orphans 10-15 years of age were held. The children were interviewed one after each other and further interviewing was terminated when there was saturation of ideas i.e. no new information was being obtained. Key informant interviews using an interview guide were held with a village chief, the village school headmaster and two teachers at the school many of the children attended. These key informant interviews with adults were held in order to validate the reports from the children. We did not aim to describe causality, objectivity, predictability or quantification of the issues (Mikkelsen, 1995).

\section{Data analysis}

Data analysis was done manually by identifying themes and isolating what was perceived as important information. The following results are based on interviews with 23 children (10 girls and 13 boys). Four were living with their mothers, 6 with a sibling, 7 with grandparents, 5 with other relatives and one with a non-relative.

\section{Results}

\section{Recurrent themes and issues}

The results are organized into following topics: basic needs and support, education, child labour, love and care, friends, health care and future aspirations of the children. At first, a story of a 12 year old girl is presented. This story in many ways was a representative of the problems that orphaned children were facing.

I have an aunt who moved away and left this house. My older sister and her husband live here. They have a one year old child. I live in my late mother's house with my 12 year old cousin. I don't have any grandparents or any other siblings. I have one uncle who works at the tea estates a few kilometres away. I don't get any support from him or from my aunt who moved away.

People in school and in the village look at me and think I'm an orphan. They treat me different. I'm not harassed when I'm among the other orphans. When I'm playing with my friends I forget a lot of things. I can forget that I'm an orphan, but sometimes when we are playing and I've done something wrong, someone can curse on me and say something about my dead parents. It makes me cry.

At times I go to school, but not often because I don't have clothes and food. When I go, it is hard sometimes because I have missed so much. A lot has been taught to my friends. I'm in standard 7. School is very important. With an education you can get a job and be independent in the future so no one can look at you and say that you're an orphan. I want to finish school and get a job and then communicate in English as you are doing now. I want to work as a nurse because they are proud of themselves. As a nurse I can assist people.

Sometimes I have a half time job at Makwasa market. Then I can earn 20 kwacha so I can buy maize that I can make into flour so I can make porridge. Sometimes I eat guava from the garden. Today my sister hasn't given me any food. I don't know why. She says "you are not eating because your mother didn't leave you anything". When she say those things it makes me cry. It makes me think of my mother and my father. My sister and her husband are the same. If my sister says I won't get food, her husband says "yes, don't give her food". 


\section{Basic needs and support}

Virtually all the children talked about lives in poverty, although the poverty could be described as varying in levels. The things that effected their situation the most were if they had a garden where they could grow food, and if they got support from the people they lived with or from anyone else. Some children had relatives who worked and helped them financially, which made a difference in the orphans' lives. The children who still lived with their mothers explained how different life was now, when they had lost their father.

The children experiencing the most poverty were the ones who are living by themselves. Several children expressed how difficult it was to live with older people. It was difficult for the grandparents to find money or food, since they are too old to work. In some cases the grandparents themselves are in need of care.

Most of the households with orphans had a garden where they could grow food, but this was almost never enough to support the household. Both the children who lived in child-headed households said that they had to find their own food, and that they almost never got any support. In most cases, the children said that they got food from their guardians, but eight of the children reported about different situations where they had been denied food from their guardians or close relatives. Almost all the children said that they did not get enough food, and that it was difficult for them to find food. Many children went to school without food, and some stayed home from school because of hunger.

In many cases, the children got support from other relatives than the ones they were living with. Sometimes they were given food by relatives who lived close, and in other cases they had relatives who have moved away to work in another area and occasionally sent money and other supplies to the orphaned children. A few children expressed difficulties in having someone further away that helped them as it was difficult for them to communicate with a far-away relation. One boy expressed that the fact that many of his siblings had been geographically dispersed made it difficult for them to assist each other. In most cases the children lacked clothes, soap, books, beddings and reasonable accommodation.
Most of the children answered that the most important person in their lives was someone who supported them with food, money and clothes. In some cases this was not the same person they were living with. When the children were asked about the most important thing in life, about half of the children answered food and clothes.

A 15 year old boy had these to say:" My grandmother is very old. My uncle and his wife live close, but the wife mistreats us. She tells her husband not to take care of me and my brother. She says that he shouldn't assist us, but she feels good when her own family members are treated well. She only gives food to her own child. My uncle does sometimes provide us with food despite his wife. My grandmother struggles to find us food, but it's very difficult for her. She tries her best to find us food, but she's very old and she doesn't do any kind of work so it's difficult for her. Many times we don't have any food at all."

\section{Education}

Almost all the children went to school sometimes, but almost half of the children said that they were often absent. The main reasons why children did not go to school was lack of food and clothes or soap to wash the clothes with. Some of them also had work to do, which affected school attendance. A few children said that it was difficult to go to school because it was too far away. All the children who go to school expressed that they found school important, and that they wanted to continue their education. Many children said that they talked with their friends about school a lot, and that school was the only thing that could help them and make them self-reliant in the future.

The children who had reached the higher standards all expressed fear that they would not be able to continue to secondary school because they could not afford the fees. The children who were living with their mothers were going to school more frequently and they have reached higher standards (classes) than the other orphans.

\section{Working experiences}

Girls had more chores to do inside the home while boys more often worked in the garden, but there were exceptions to this. A few of the children expressed that the work they did in the home is not too much on them, while some children 
expressed that the work they did was too much and that it was hard and tiresome. There were children who were being told by others in the family to do more work than they felt they were able to do, and a few mentioned being yelled at for not doing something they were supposed to do. A few children living with elderly people expressed that their caretakers were too old to take care of the household, which led them (the children) having more work to do.

"It is difficult for us to find food. My grandparents are not able to find part-time jobs. My grandfather is old and now he has been sick. We have one vegetable garden and one maize garden. It is mostly me who takes care of the gardens, since my grandmother takes care of my grandfather. But it is difficult for me to manage both gardens since I am in school" (13 year old boy).

Some children had part-time jobs where they earn some extra money. The two children living in child-headed households both had part time jobs. Work, both in the households and part-time jobs, was perceived as having a negative effect on school attendance for several children as alluded by one 13 years old boy: "I've been living alone with my sister for eight years, and we don't get any support from anyone else. Most of the times, I don't go to school because I don't have food. When I don't go to school I go to the tea estates to get a job so I can buy soap and then go to school. It is very tiresome to work at the estates, but my sister insults me when I don't go. When I don't have a job she doesn't give me any food. She tries to push me to get a job, but I don't always go because it's too hard for me. Many times I'm absent from school, because I don't have any clothes. I go for two weeks and then my clothes are dirty so I can't go. I like school very much, and I would like to go more often. At times my sister insults me. She says "I'm tired of you, go away. Support yourself." She does that because she thinks I'm old enough to get married and support myself, but I still think I'm young and I want to go to school. School is important because then you can support yourself, be independent and stay wherever you want to stay."

\section{Love, care and discrimination}

Most of the children had someone to talk to if they had a problem and if there was something they needed. As mentioned earlier this could be someone living both inside or outside the home, but it was not always that this person would necessarily help them with their needs. Many of the children expressed that they could always rely on people in their surroundings to help them. Some of the children however had someone who would try their best to be able to help them. In a few cases, the children did not have anyone to talk to about problems, and some children expressed that being an orphan meant that one had to work hard to get things and ought to fix things for self.

More that half of the children felt that they were treated in a bad or different way within the family or within the household they were living. This was often about being denied food but also being talked to in a bad way, or in the distribution household work. Some children talked about being treated differently in the village i.e. further away from the home. The children living in child headed households were more exposed to discrimination in the village. Many of them expressed that this made them feel very sad.

"I don't get along with people in the village. They quarrel with me and shout at me 'you orphan, you orphan'. People fight with me and one man threw a bottle at me so I got a wound under my knee. I had to struggle to find medicine. They do these types of things because I don't have any parents....This makes me feel bad. I think that if I had parents this wouldn't have happened, but there is nothing I can do about it so I just let them do what they are doing" (15 year old boy).

Many of the children talked about the importance of having parents, and some of them suggested that it was only one's own parents who can take care of a child properly, especially the mother. They said that parents would not treat them the way others did, and that other people would not treat them in a particular way if their parents were alive. Some children envied friends for having parents and for having things like clothes, food and soap, as testified by a 13-years old girl: "Mom and dad are the only ones who can care of you in anything and everything. I am treated differently because I am an orphan. If I had a mother my grandmother wouldn't curse on me."

Three of the four children who still had their mother said that their mother was the most important person in their lives. The fourth child said that his grandparents were more important than his mother because they are the ones who were mostly responsible for food for the household. One child reported that 
temptation to stealing was strong, although he also said that he knew that if he would steal and caught, it would just give him more problems than he already had.

Some children living with grandparents talked about being loved by them and that they felt encouraged. At the same time many of them also said that the grandparents were too old to take care of them. There were also situations where the children reported that grandparents could treat them badly.

\section{Friends}

Almost all the children had friends who they thought were useful, and who they felt they could communicate well with. The children expressed that important attributes of friends were that they should communicate well and understand each other, that they should not lie and that they should be on your side. Playing with friends made many children feel happy. Some children said that they talk to their friends about problems and worries they had. Some of them reported that they sometimes got help from friends by being given or lent things like food or a pen. Some children said if when they had good friends those friends would help them with food. More than half of the children said that when they were with friends they discussed school and helped each other with schoolwork. Some children had friends who were also orphans. They expressed that it was easier to understand each other when both were in the same situation. They preferred to spend time with children who were also orphans because among them it was almost impossible to get harassed, for being an orphan.

Some of the children reported about situations when they were playing with their friends and someone might say things about their late parents. One boy expressed being excluded in games because he was an orphan, while a 12 year old girl had these to say: "At times when I play with friends they mention my parents saying 'your parents died of AIDS'. That makes me sad. Maybe they do that because they have parents. Sometimes I talk to my uncle and sometimes I talk to friends about what others are saying." On the other hand, a 13 year old boy said: "I' $m$ treated differently because I am an orphan. When this happens I go and meet my fellow orphans. It could be that when we are in a group playing someone can keep me aside and say 'We don't have to include him in what we are doing, because he is an orphan'. This makes me feel sad. Then I go to my fellow orphans. When we are together we plan for the next day and what we are going to do in school the next day. I admire friends who have both parents. I think about losing both parents, and it makes me sad."

One girl talked about the difference between orphan girls and girls who still have their parents. No one else mentioned this problem, but this is how she put it: "My friends are fine. We talk about school and encourage each other to work hard in class. A good friend is the one who doesn't mention anything about boys. My friends don't talk about boys because we are all orphans. Some of the other children talk about boys. They say they want to get money from boys. We orphans always talk about school. We know that if we meet boys and get pregnant we won't finish school and we will have problems. Those children who have parents are not as concerned, because they know that their parents will take care of them if they get pregnant"(13 year old girl).

\section{Health care}

All the children who still had mothers said that the mother was responsible for them when they were sick, and all the children said that there was someone who would take care of them in the event of an illness. In some cases it is not the person the child stayed with who took care of them. Instead some other relative took the responsibility, especially when money was an issue, or when the primary care giver was very old. Most of the children expressed that because of lack of money in the household, it was difficult to go to the hospital. Some said that they always went to the hospital if they need to, but most of the children said that it is too expensive and that they rather buy medicine at the market.

\section{Perception of the future}

Orphans expressed of the hopelessness future as exemplified by two children. A 12 year old boy had these to say: "When you lose both parents you don't know what's going to happen in the future, so you're always a sad person". A 11 year old girl added that: "I'm worried that even though you might have wishes, you might die before you get there"

All the children who were in school said they wish to finish their education. They all said that education would help them to find formal employment so they could be financially independent. Almost all the children expressed dreams about a certain job or profession, most frequently being teacher, doctor, nurse, secretary or to work in an office. 
Some of the children wished to move away from the village in the future, while others wish to stay. Several children expressed worries about the future. In many cases these worries were about the possible lack of school fees for secondary school. "I want to finish my education and get a good job. I want to work in an office, because it's a paid job, and then I can assist my relatives. I'm worried that I won't have anyone who can pay the fees for secondary school if I'm selected. What will happen if I get selected? Who will pay? I think that no one will pay, and instead I will just be staying here at home doing nothing" (said a 14 year old boy).

\section{Key informant interviews}

The reports from the key informants (village chief, a school headmaster and two teachers were held to obtain a general socio-economic perspective of the area and validate the findings from the reports from the children. There was significant agreement between what the key informants reported and what had been reported by the children.

\section{Discussion}

The vulnerability of orphans in rural Thyolo district, southern Malawi occurs at several fronts namely, education, health, basic needs, friendship and companionship, love and prospects for a better future. The area is served by a large hospital fee-for-service hospital. The cost of care may however be unaffordable to the majority of orphans and other poor populations. There is no free public health facility as the agreement between the denominational hospitals in rural areas and the Ministry of Health is such that government should not have a free-public health institution within 10 kilometres of a mission hospital.

Many of the children reported having to work hard to support themselves, and in some cases also to support others. Some of the children reported being exposed to discrimination and stigma, both from family members and from others in the village. Children who were most exposed to poverty were also most exposed to discrimination. Not surprisingly, orphaned children were likely to be accepted by other orphaned children. Crampin et al. (2003), in their study in northern Malawi however, reported that orphan children were not discriminated against and their nutritional status was comparable to non-orphaned children. Two differences between northern and southern Malawi are that the south is much poorer and has matrilineal culture. Sarker et al. (2000) have also reported in their study from Kampala, Uganda that the health and nutrition status of orphans were similar to non-orphaned children.

Many children expressed that the only persons that could take good care of them were their parents. A support mechanism that several orphans seemed to have developed was to turn to different persons for different kinds of support. They accepted the help they could get in their home, but when it was perceived as not adequate they turned to other people. Relatives in the village were also an important source of help with food or soap, and relatives living elsewhere else could send money and other supplies.

Many of the children were not able to attend school as much as they would have liked to get the education they needed. The fact that much of the public free primary school education was dilapidated with low quality of education is likely to impact of the orphan children's dream as compared to other children who may be able to access private, fee-paying primary education. While primary education is free in Malawi, secondary education is not. Orphan children expressed possible difficulties in fees in case they were to attend secondary education. The difficulties they were likely to face to access secondary education were likely to impede of their dreams. It is also important to realise that formal education may not work to all children and training in vocational skills may be an important aspect in the orphan child's social development (Mann, 2000).

There are many different models of orphan care, three of which are communitybased, institutional residential care and self-care (Beard, 2005). The official policy in Malawi is that the extended family, caring the orphan within the community is the preferable form. The extended family, although preferred by national policy, may not fit all situations. The spatial dispersion of the extended family may mean migration and separation of siblings (Abrahamsson, 2003; Ansell \& Young, 2004). There is need to evaluate the resilience of the extended family structure with the increasing numbers of orphans and the fastdeclining of the adult population. Also the fact 
that many older adults are living with doubleorphans must be factored into all programmes aimed at supporting the caring of orphans within the community and extended family network (Zimmer \& Dayton, 2005). Programmes also need to consider the effects of Hamilton rule, which states that closeness of biological ties governs altruistic behaviour i.e. the more closer the guardian to an orphan is, the more likely the guardian will sacrifice in the best interest of the child (Case et al., 2004).

Innovative measures to improve the economic situation of poor rural household caring for orphans are needed. Sherer et al. (2004) reported on the village health bank initiative in Guatemala, Malawi and Thailand that improved the economic situation, nutrition status and school attendance amongst poor households. In Tanzania, Kayombo et al. (2005) have reported on an initiative where traditional healers were critical in offering psychosocial support to orphans in Tanzania.

In conclusion, orphans in rural Malawi face significant challenges in terms of obtaining daily necessities of living as well as resources which would enable them to prepare for economically productive future. There is need for interventions that not only address present needs but also facilitates preparation for a productive future.

\section{Acknowledgements}

We are grateful to the community and the orphan children for allowing us to conduct the study.

\section{References}

Abrahamsson, M. (2003) AIDS Orphans in Malawi. The impact of orphans on the extended family safety net due to HIV/ AIDS. Kulturgeografiska institutionen, University of Uppsala, Sweden.

Ansell, N. \& Young, L. (2004) Enabling household to support successful migration of AIDS orphans in southern Africa. AIDS Care 16, 3-10.

Beard, B.J. (2005) Orphan care in Malawi: current practices. Journal of Community Health Nursing 22, 105-115.

Brody, S. (2004) Declining HIV rates in Uganda: due to cleaners needles, not abstinence or condoms. International Journal of STDs $\mathcal{E}$ AIDS 15, 440-441.
Case, A., Paxson, C. \& Ableidinger, J. (2004) Orphans in Africa: parental death, poverty, and school enrolment. Demography 41, 483-508.

Crampin, A.C., Floyd, S., Glynn, J.R., Madise, N., Nyondo, A., Khondowe, M.M., Njoka, C.L., Kanyongoloka, H., Ngwira, B., Zaba, B. \& Fine, P.E.(2003) The long-term impact of HIV and orphan hood on the mortality and physical well-being of children in rural Malawi. AIDS 17, 389397.

Delva, W., Vercoutere, A., Dehaene, I., Willems, S., Temmerman, M. \& Annemans, L. (1995) Thinking ahead-the rising tide of AIDS orphans. South African Medical Journal 95, 656-658.

Drew, R.S., Makufa, C. \& Foster, G. (1998) Strategies for promoting care and support to children orphaned by AIDS. AIDS Care 10, Suppl 1, S9-15.

Gibbons, J.A. (2005) Orphanages in Egypt. Journal of Asian and African Studies 40, 261-285.

Kayombo, E.J., Mbwambo, Z.H. \& Massila, M. (2005) Role of traditional healers in psychosocial support in caring for the orphans: A case of Dar-es-Salaam City, Tanzania. Journal of Ethnobiology and Ethnomedicine 1, 3.

Mann, G. (2002) Family Matters: the Care and Protection of Children Affected by HIV/AIDS in Malawi. Save the Children, Sweden.

Manzi, M., Zachariah, R., Teck, R., Buhendwa, L., Kazima, J., Bakali, E., Firmenich, P., \& Humblet, P. (2005) High acceptability of voluntary and HIV-testing but unacceptable loss to follow-up in a prevention of mother to child HIV transmission programme in rural Malawi: scaling-up requires a different way of acting. Tropical Medicine and International Health 10, 1242-1250.

Michelo, C., Sandoy, I.F. \& Fylkesnes, K. (2006) Marked HIV prevalence declines in higher educated young people: evidence from population-based surveys (19952003) in Zambia. AIDS 20, 1031-1038.

Mikkelsen B. (1995) Methods for Developing Work and Research. Sage Publications, India.

Murphy, E.M., Greene, M.E., Mihailovic, A. \& Olupot-Olupot, P. (2006) Was the "ABC" approach (abstinence, being faithful, 
using condoms) responsible for Uganda's decline in HIV? PLoS Med 3, e379.

Muula, A.S., Misiri, H., Munthali, L., Kalengo, S., Kachali, F., Mbewe, M. \& Msuku, S. (2003) The living situations of orphans in peri-urban Blantyre, Malawi. South African Medical Journal 93, 920-921.

National AIDS Commission (2005) HIV / AIDS in Malawi. 2005 HIV Estimates of the Prevalence. National AIDS Commission, Lilongwe, Malawi.

Sarker, M., Neckermann, C. \& Muller, O. (2000) Assessing the health status of young AIDS and other orphans in Kampala, Uganda. Tropical Medicine and International Health 10, 210-215.

Sherer, R.D. Jr, Bronson, J.D., Teter, C.J.R. \& Wykoff, R.F. (2004) Microeconomic loans and health education to families in impoverished communities: implications for the HIV pandemic. Journal of the International Associations of Physicians in AIDS Care 3, 110-114.

UNAIDS (2006) UNAIDS Report on the Global Epidemic, 2006 Geneva.

UNICEF \& UNAIDS (1999) Children orphaned by AIDS: Front-line Responses from Eastern and Southern Africa, UNICEF.
World University Service of Canada 2004) The impact of the HIV/AIDS pandemic on orphan care in Malawi: the role of civil society, government, and the extended family, 2004. Accessed on July 12, 2006 at www. wusc.ca / campuses / overseas / seminar / malawi2004/aidsmlw3.asp

Zachariah, R., Harries, A.D., Arendt, V., Wennig, R., Schneider, S., Spielmann, M., Panarotto, E., Gomani, P. \& Salaniponi, F.M. (2001) Compliance with cotrimoxazole prophylaxis for the prevention of opportunistic infections in HIV-positive tuberculosis in patients in Thyolo District, Malawi. International Journal of Tuberculosis and Lung Diseases $5,843-846$.

Zachariah, R., Teck, R., Buhendwa, L., Labana, S., Chinji, C., Humblet, P. \& Harries, A.D. (2006) How can the community contribute in the fight against HIV / AIDS and tuberculosis? An example from a rural district in Malawi? Transactions of the Royal Society of Tropical Medicine and Hygiene 100, 167-175.

Zimmer, Z. \& Dayton, J. (2005) Older adults in sub Saharan Africa living with children and grand children. Population Studies 59, 295-312. 